\title{
PREFACE TO THE \\ THIRD EDITION
}

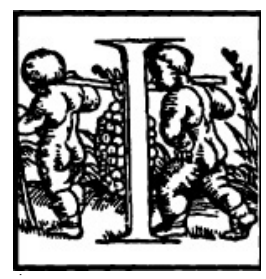

$n$ the second edition of this handbook, I added a considerable bit of new material; this included some non-Western verse forms influential to poets writing in English; a discussion of what the late W. K. Wimsatt called "verbal mimesis"; and some examples, selfdescriptive in various ways-such as sonnets on the sonnet-of verse forms by other poets from the seventeenth through the twentieth centuries. This considerably augmented third edition allows the schemes and patterns illustrated self-descriptively additional room to speak for themselves, as it were, through instances of their actual use in poetry. These are collected in the section Patterns in Practice at the end of this volume and will additionally exemplify the ways in which different historical styles of diction and syntax, and changing conceptions of genre, have subtly recast older formal patterns and devices.

I should like to head off any possible misleading characterization of this book as a guide to "formal poetry." The very term itself seems a misnomer: it implies that accentual-syllabic verse is the only 
"form," and that the many different kinds of freeverse, of twentieth-century syllabics, of pure accentualism, etc., are formless. This is nonsense. There is a great difference between coherent writing and incoherent or dysfunctional writing in verse of any sort. And surely poetic "form" is a very deep matter that covers much more than phonological or typographic pattern. I have discussed such matters in some detail elsewhere; but a reader who considers closely the array of examples now included will probably be able to see into some of these depths.

Since the original edition of this manual twenty years ago, I have noticed that a considerable number of good younger poets are now writing accentualsyllabic (rhymed or blank) or syllabic verse with deep skill, or various modes of free verse that generate their own conventions and rules with the same kind of power that measured verse deploys. This is perhaps because a century-long tradition of great poetry written in free verse can supply models, not for imitation, but-and this is true of all poetic verbal patterns-for creative revision. And yet the preponderance of very bad verse is still the same weak vers libre that has all of the inanity of the rhymed greetingcard jingle that was the analogous default-mode of badly written verse in the first half of the twentieth century. Good verse of any sort is nevertheless only half the story of good poetry, whose essential character is what Wallace Stevens called "fictive," and Robert Frost "ulterior," or "saying one thing and meaning another," or what we could simply call not being literal. Having in the past year spent time re- 
covering from an injury, I came to realize that "When you see someone with a cane / That person's probably in pain."

These lines are clearly verse, and the proposition they assert is true. But they are not in the least poetry, for they are totally literal: there is nothing of fiction in them. Even the one possible trace of the nonliteral that might lurk therein-that pain and cane appropriately rhyme because feeling the first might lead one to use the second - is totally glossed into triviality by the simple literal truth of the statement. Rhyme's Reason is thus subtitled A Guide to English Verse and not "-to Poetry." I trust that its readers will understand that verse (or in certain modern instances, prose treated and used as verse) is a necessary but not a sufficient condition for poetry. All the rest is metaphor.

I hope that immediate reminders of the actual poetic use of the patterns and schemes will inform readers' subsequent experience of the whole of poetry in our language.

I have corrected a few minor errors and added to the main body of the text some material on conventions of typographical indentation in verse. In addition I should like to add the following to the "Suggestions for Further Reading" section on page 137-138: Paul Fry's The Poet's Calling in the English Ode (New Haven, 1980); Jennifer Wagner's Moment's Monument: Revisionary Poetics and the Nineteenth-Century Sonnet (Madison, N.J., 1996); John Fuller's The Sonnet (London, 1972); Stephen Cushman's Fictions of Form in Modern Poetry (Princeton, 1993); Richard Brad- 
ford's The Look of It: A Theory of Visual Form in English Poetry (Cork, Ireland, 1993); Annie Finch's The Ghost of Meter: Culture and Prosody in American Free Verse (Ann Arbor, 1993); H. T. Kirby-Smith's The Origins of Free Verse (Ann Arbor, 1996); and Steven Monte's Invisible Fences: Prose Poetry as a Genre in French and American Literature (Lincoln, Nebr., 2000).

I wish to thank Donald Hall and Alan Ansen for permission to include their splendidly self-regarding sestinas. 